\title{
A Comparative Study on Simultaneous Determination and Separation of Adsorbed Cadmium Oxide (CdO) Nanoparticles on DNA/RNA of Human Cancer Cells Using Biospectroscopic Techniques and Dielectrophoresis (DEP) Method
}

A Heidari

Faculty of Chemistry, California South University, 14731 Comet St. Irvine, CA 92604, USA

Corresponding author: A Heidari, Faculty of Chemistry, California South University (CSU), 14731 Comet St. Irvine, CA 92604, USA, Tel: 1-775-410-4974; E-mail: Scholar.Researcher.Scientist@gmail.com

Received: 26 June 2016; Accepted: 28 June 2016; Published: 30 June 2016

Citation: A Heidari. A Comparative Study on Simultaneous Determination and Separation of Adsorbed Cadmium Oxide (CdO) Nanoparticles on DNA/RNA of Human Cancer Cells Using Biospectroscopic Techniques and Dielectrophoresis (DEP) Method. Arch Can Res. $2016,4: 2$.

\section{Editorial}

During recent years the universal interest in trace elements has simulated a number of studies of their concentration and distribution in the human cancer cells, with the purpose of establishing the normal values and also to detect cancer, occupational cancer and toxic effects [1-21]. Nanoparticles exist in the environment and in a variety of compounds with different properties [22-32]. In this editorial, a novel, simple and sensitive direct method has been developed for determination of nanoparticles in human cancer cells using biospectroscopic techniques such as ${ }^{1} \mathrm{HNMR},{ }^{13} \mathrm{CNMR}$, ${ }^{31}$ PNMR, Attenuated Total Reflectance Fourier Transform Infrared (ATR-FTIR), FT-Raman, HR Mass and UV-Vis spectroscopies. The repeatability of the measurements of whole procedure was excellent. The accuracy and precision of the method has been investigated by measurement of nanoparticles in human cancer cells' samples and compared the results with H-Point Standard Addition Method (HPSAM)'s results. The results were in good, reasonable and acceptable agreement with the $\mathrm{H}$-Point Standard Addition Method (HPSAM).

On the other hand, Dielectrophoresis (DEP) is a controlled movement of uncharged polarizable nanoparticles in a nonuniform electric field that used a separation method in human cancer cells [33-61]. In this editorial have been studied dielectrophoretic behaviors of human cancer cells and fine nanoparticles such as Cadmium Oxide (CdO) nanoparticles adsorbed on DNA/RNA of human cancer cells shows that the polarization of the nanoparticles is dominated by solution conductance. In this method, several kinds of electrode arrays are employed for separation.

Furthermore, in this editorial, the H-Point Standard Addition Method (HPSAM) based on biospectroscopic techniques such as ${ }^{1} \mathrm{HNMR},{ }^{13} \mathrm{CNMR},{ }^{31} \mathrm{PNMR}$, Attenuated Total Reflectance Fourier Transform Infrared (ATR-FTIR), FTRaman, HR Mass and UV-Vis spectroscopies for simultaneous determination of nanoparticles in human cancer cells is investigated. This method is based on the difference between their rates of reactions with Cadmium Oxide (CdO) nanoparticles in the presence of DNA/RNA of human cancer cells. The results showed that nanoparticles in human cancer cells can be determined simultaneously with the concentration ratios of Cadmium Oxide (CdO) nanoparticles varying from 1: 5 to 1: 50 in the binary mixture samples. It should be noted that under working conditions, the proposed method was successfully applied to the simultaneous determination of nanoparticles in human cancer cells.

\section{References}

Kumar RTK, Liu S, Minna JD, Prasad S (2016) Monitoring drug induced apoptosis and treatment sensitivity in non-small cell lung carcinoma using dielectrophoresis. Biochimica et Biophysica Acta 1860: 1877-1883.

Yamaguchi A, Fukuoka T, Takahashi R, Hara R, Utsumi Y (2016) Dielectrophoresis-enabled surface enhanced Raman scattering on gold-decorated polystyrene microparticle in microoptofluidic devices for high-sensitive detection. Sensors and Actuators B: Chemical 230: 94-100.

Lee D, Hwang B, Choi Y, Kim B (2016) A novel dielectrophoresis activated cell sorter (DACS) to evaluate the apoptotic rate of K562 cells treated with arsenic trioxide (As2O3). Sensors and Actuators A: Physical 242: 1-8.

4. Gutiérrez MA, Khanbareh H, Zwaag SVD (2016) Computational modeling of structure formation during dielectrophoresis in particulate composites. Computational Materials Science 112: 139-146.

Tian K, Decker K, Aksimentiev A, Gu L (2016) Microcarrierguided nanopore dielectrophoresis for selective nucleic acid detection. Biophysical Journal 110: 502a.

6. Xie C, Chen B, Liu L, Chen H, Wu J (2016) Iterative dipole moment method for the interaction of multiple dielectrophoretic particles in an AC electrical field. European Journal of Mechanics - B/Fluids 58: 50-58.

Sharma A, Han C, Jang J (2016) Rapid electrical immunoassay of the cardiac biomarker troponin I through dielectrophoretic concentration using imbedded electrodes. Biosensors and Bioelectronics 82: 78-84.

Wuethrich A, Haddad PR, Quirino JP (2016) The electric field An emerging driver in sample preparation. TrAC Trends in Analytical Chemistry 80: 604-611. 
9. Smallwood J, Praeger M, Chippendale R, Lewin P (2016) Dielectrophoretic adhesion of 50-300 $\mu \mathrm{m}$ particles under ambient atmospheric conditions. Journal of Electrostatics 82 : 1-6.

10. Chuang C, Du Y, Wu T, Chen C, Lee D, et al. (2016) Immunosensor for the ultrasensitive and quantitative detection of bladder cancer in point of care testing. Biosensors and Bioelectronics 84: 126-132.

11. Oliva-Avilés Al, Zozulya VV, Gamboa F, Avilés F (2016) Dynamic evolution of interacting carbon nanotubes suspended in a fluid using a dielectrophoretic framework. Physica E: Lowdimensional Systems and Nanostructures 83: 7-21.

12. Magliano A, Camarda M, Lombardo SF, Martino RD, Cascio M, et al. (2016) Elution time changes due to anomalous DEP effects in microchannels under uniform and non-uniform electric fields. Sensing and Bio-Sensing Research 8: 59-64.

13. Sano N, Tanemori Y, Tamon H (2016) A selective dielectrophoretic particle separator using flat electrodes covered with vertically aligned carbon nanotubes. Chemical Engineering Science 144: 321-325.

14. Liu W, Wang C, Ding H, Shao J, Ding Y (2016) AC electric field induced dielectrophoretic assembly behavior of gold nanoparticles in a wide frequency range. Applied Surface Science 370: 184-192.

15. Baldo S, Buccheri S, Ballo A, Camarda M, Magna AL, et al. (2016) Carbon nanotube-based sensing devices for human Arginase-1 detection. Sensing and Bio-Sensing Research. 7: 168-173.

16. Bakewell DJ, Bailey J, Holmes D (2016) Exploring and evaluating micro-environment and nanoparticle dielectrophoretic-induced interactions with image analysis methods. Materials Today: Proceedings 3: 867-874.

17. Dash S, Mohanty S, Pradhan S, Mishra BK (2016) CFD design of a microfluidic device for continuous dielectrophoretic separation of charged gold nanoparticles. Journal of the Taiwan Institute of Chemical Engineers 58: 39-48.

18. St. Kreibik CV (2016) Layer dielectrochromatography-under external alternating current, LDEC, in forced-flow layer chromatography, Ernő Tyihák (ed.), Elsevier, Boston 285-345.

19. Mavrogiannis N, Crivellari F, Gagnon ZR (2016) Label-free biomolecular detection at electrically displaced liquid interfaces using interfacial electrokinetic transduction (IET). Biosensors and Bioelectronics 77: 790-798.

20. Martino RD, Camarda M, Cascio M, Gallo M, Magliano A, et al. (2016) Analysis of the role of elution buffers on the separation capabilities of dielectrophoretic devices. Sensing and BioSensing Research 7: 162-167.

21. Hyon J, Seo C, Yoo I, Song S, Kang Y (2016) Glassy photonic inks encapsulated in core-shell microcapsules for local electric field sensors. Sensors and Actuators B: Chemical 223: 878-883.

22. Miccio L, Marchesano V, Mugnano M, Grilli S, Ferraro P (2016) Light induced DEP for immobilizing and orienting Escherichia coli bacteria. Optics and Lasers in Engineering 76: 34-39.

23. Cui H, Cheng C, Lin X, Wu J, Chen J, et al. (2016) Rapid and sensitive detection of small biomolecule by capacitive sensing and low field AC electrothermal effect. Sensors and Actuators B: Chemical 226: 245-253.

24. Karle M, Vashist SK, Zengerle R, Stetten FV (2016) Microfluidic solutions enabling continuous processing and monitoring of biological samples: A review. Analytica Chimica Acta 929: 1-22.
25. Leahy S, Lai Y (2016) An hourglass design with electrokinetic sampling and electrothermal actuation for micro biosensors. Sensors and Actuators B: Chemical 223: 123-130.

26. Samanta A, Nandan B, Srivastava RK (2016) Morphology of electrospun fibers derived from high internal phase emulsions. Journal of Colloid and Interface Science 471: 29-36.

27. Charoonrak N, Tungkavet T, Sirivat A, Lerdwijitjarud W (2016) Poly(p-phenylene)/crosslinked poly( $\varepsilon$-caprolactone) blends as highly electroactive materials. Materials Chemistry and Physics 171: 359-366.

28. Lee M, Kim D (2016) Au nanoparticles attached carbon nanotubes as a high performance active element in field effect transistor. Materials Chemistry and Physics 179: 103-109.

29. Kumar D, Kumar I, Chaturvedi P, Chouksey A, Tandon RP, et al. (2016) Study of simultaneous reversible and irreversible adsorption on single-walled carbon nanotube gas sensor. Materials Chemistry and Physics 177: 276-282.

30. Sangwan W, Petcharoen K, Paradee N, Lerdwijitjarud W, Sirivat A (2016) Electrically responsive materials based on polycarbazole/ sodium alginate hydrogel blend for soft and flexible actuator application. Carbohydrate Polymers 151: 213-222.

31. Vikash K, Pouya R (2016) Magnetic focusing and hydrodynamic deflection of micro-particles in a microdevice. Biophysical Journal 110: 503.

32. Siddharth D, Yaron C, Anthony B, Cees D (2016) A microfluidic platform to produce and manipulate liposomes - towards synthetic cells on chip. Biophysical Journal 110: 17

33. Xiaohong J, Meng Y, He L, Li L, Du Z (2016) Optoelectronic properties of one-dimensional fullerene nanorods. Materials Letters 176: 52-55.

34. Kasif T (2016) Photoresponse characteristics of silicon carbide nanowires. Microelectronic Engineering 162: 79-81.

35. Matta C, Lewis R, Barrett-Jolley R, Labeed FH, Hughes MP, et al. (2016) Ion channel expression and function in a chondrogenic progenitor cell line derived from osteoarthritic cartilage. Osteoarthritis and Cartilage 24: 141

36. Sang WL (2016) Mechanical properties of suspended individual carbon nanotube studied by atomic force microscope. Synthetic Metals 216: 88-92.

37. Yizhi S, Huabing Y, Wei EH (2016) Raman activated cell sorting. Current Opinion in Chemical Biology 33: 1-8.

38. Constantin L, Reasmey $\mathrm{T}$, Julien $\mathrm{D}$, Simon $\mathrm{T}$, Gábor $\mathrm{M}$, et al. (2016) Unidirectional electric field-induced spin-state switching in spin crossover based microelectronic devices, Chemical Physics Letters 644: 138-141.

39. Kiho K, Jooheon K (2016) Magnetic aligned AIN/epoxy composite for thermal conductivity enhancement at low filler content, Composites Part B: Engineering 93: 67-74.

40. Qitao Z, Taesung K (2016) Review of microfluidic approaches for surface-enhanced Raman scattering, Sensors and Actuators B: Chemical 227: 504-514.

41. Guimei Y, Kunpeng L, Wen J (2016) Antibody-based affinity cryoEM grid. Methods 100: 16-24.

42. Karat P, Anuvat S (2016) Magneto-electro-responsive material based on magnetite nanoparticles/polyurethane composites, Materials Science and Engineering: C 61: 312-323. 
43. Kiho K, Hyun J, Jooheon K (2016) Filler orientation of boron nitride composite via external electric field for thermal conductivity enhancement, Ceramics International 42: 8657-8663.

44. Amy R, Bingzhao X, Zhongliang J, Benjamin N, Ralph MB, et al. (2016) Microfluidic techniques for high throughput single cell analysis, Current Opinion in Biotechnology 40: 90-96.

45. Ki-Young S, Kenichi M, Yu-Chung C, Yuji S (2016) Electrostatic instability of liquid droplets on MEMS-based pillared surfaces. Sensors and Actuators B: Chemical 225: 492-497.

46. Yung-Chiang C, Chen-Ming W, Shih-Hao L (2016) Particles sorting in micro channel using designed micro electromagnets of magnetic field gradient. Journal of Magnetism and Magnetic Materials 407: 209-217.

47. Myeongsoon L, Don K (2016) Non-enzymatic carbohydrates detection based on Au modified MWCNT field-effect transistor, Materials Letters 169: 257-261.

48. Siwoo C, Wonju J, Youhee H, Yoon KJ, Rhokyun K, et al. (2016) Isolation of extracellular vesicle from blood plasma using electrophoretic migration through porous membrane. Sensors and Actuators B: Chemical 233: 289-297.

49. Selmi M, Khemiri R, Echouchene F, Belmabrouk H (2016) Electrothermal effect on the immunoassay in a microchannel of a biosensor with asymmetrical interdigitated electrodes. Applied Thermal Engineering 105: 77-84.

50. Roberta M, Giulia G, Pietro F, Andrea R, Francesco F (2016) CTCs in early breast cancer: A path worth taking, Cancer Letters 376: 205-210.

51. Perret $G$, Ginet $P$, Tarhan MC, Baccouche A, Lacornerie $T$, et al. (2016) Nano systems and devices for applications in biology and nanotechnology. Solid-State Electronics 115: 66-73.

52. Burak D (2016) Applying the miniaturization technologies for biosensor design. Biosensors and Bioelectronics 79: 901-913.

53. Rishad RJ, Gaurang JL, Dhaval DP, Laxman DP, Nurrudin PJ, et al (2016) Biomedical microelectromechanical systems (BioMEMS):
Revolution in drug delivery and analytical techniques. Saudi Pharmaceutical Journal 24: 1-20.

54. Young KH, Seokho K, Hyeong TK, Sunkook K, Bong-Gi K, et al. (2016) Multifunctional $\pi$-conjugated poly (3-methylthiophene) nanotubes for optoelectronic and field emissive devices. Organic Electronics 32: 59-64.

55. Sawsen A, Mounir BA, Mohammed NA, Joan B, Nadia Z, et al. (2016) Novel iron (III) phthalocyanine derivative functionalized semiconductor based transducers for the detection of citrate. Organic Electronics 34: 200-207.

56. Yi L, Qinlong R, Tingting L, Siu L, Vincent G, et al. (2016) Longrange electrothermal fluid motion in microfluidic systems. International Journal of Heat and Mass Transfer 98: 341-349.

57. Pei L, Lei H, Fei W, Valery AP, Aihua L (2016) Gold nanoprobe functionalized with specific fusion protein selection from phage display and its application in rapid, selective and sensitive colorimetric biosensing of Staphylococcus aureus, Biosensors and Bioelectronics 82: 195-203.

58. Mesrop A, James DO (2016) The viable but non-culturable state and its relevance in food safety. Current Opinion in Food Science 8: 127-133.

59. Joshua L, Robert JY, Pedro CM, Cornelia W, Eric TW (2016) TT Fields Therapy: Preclinical and clinical data. In: Handbook of Neuro-Oncology Neuroimaging (2ndedn), Herbert B. Newton (eds.), Academic Press, San Diego 243-256.

60. Damien LR, Gorky S, Richard H, Klaus H, Frédéric D (2016) Fabrication and characterization of polymer membranes with integrated arrays of high performance micro-magnets. In: Dominique Givord, Nora M. Dempsey (eds.) Materials Today Communications 6: 50-55.

61. Zeyang L, Masaru T, Masahiro N, Yasuhisa H, Qiang $H$, et al. (2016) Shape-controlled high cell-density microcapsules by electrodeposition. Acta Biomaterialia 37: 93-100. 